\title{
A CONSTITUIÇÃO MÃE: A CRF/88 E O ARQUÉTIPO MATERNO
}

\author{
THE MOTHER'S CONSTITUTION: THE CRF / 88 AND THE \\ MATERNAL ARCHETYPE
}

Florisvaldo Marques de SOUZA JÚNIOR ${ }^{1}$

ISSUE DOI: $10.21207 / 1983.4225 .586$

\begin{abstract}
RESUMO
Este trabalho pretende uma aproximação entre o Direito Constitucional e a Psicologia Analítica, numa leitura interdisciplinar, demonstrando os traços do arquétipo materno na Constituição da República Federativa do Brasil de 1988, esperando-se que sua leitura resulte em maior conscientização dos juristas a respeito da psique inconsciente e da dimensão anímica da CRF/88.
\end{abstract}

Palavras-chave: Constituição da República Federativa do Brasil de 1988. Psicologia Analítica. Inconsciente coletivo. Arquétipo materno. Constituição simbólica.

\section{ABSTRACT}

This work intends an approximation between the Constitutional Law and Analytical Psychology, in an interdisciplinary reading, demonstrating the traits of the maternal archetype in the Constitution of the Republic Federative of Brazil of 1988, hoping that its reading will result in a greater awareness of the jurists regarding the psyche unconscious and of the soul dimension of the CRF / 88 .

Keywords: Constitution of the Federative Republic of Brazil of 1988. Analytical Psychology. Collective unconscious. Maternal archetype. Symbolic constitution.

\footnotetext{
${ }^{1}$ Acadêmico do Curso de Direito da Universidade do Vale do Itajaí/SC - UNIVALI, cursando o $9^{\circ}$ Período. Tecnólogo em Comércio Exterior pela Faculdade de Tecnologia Internacional - FATEC (2010), Curitiba/PR. Ex Técnico Federal de Controle Interno da Controladoria-Geral da União no Paraná (2001-2005). Atualmente, Técnico Judiciário, Subseção Judiciária da Justiça Federal de Santa Catarina. e e-mail: juniordeitajai@univali.edu.br..
} 


\section{INTRODUÇÃO}

"VOCATUS ATQUAE NON VOCATUS DEUS ADERIT"(Evocado ou não o Deus se manifesta) Portal de Delfos

A CRF/88 parece possuir um quê de mãe, perceptível em suas múltiplas promessas aconchegantes, entre elas: as de justiça social, erradicação da pobreza, saúde e educação gratuita para todos, assistência social sem contrapartida financeira, etc. Desejos constitucionais sem preocupação com a realidade e possibilidades das bases econômicas e fatores de produção nacional. Desconfia-se que tudo isso são gostosos calor e ternura, características daquilo que é maternal, desconfia-se que o constituinte originário tenha sido influenciado por disposições psíquicas inconscientes que emergiram no Texto-Mor de 1988.

Do inconsciente tratou abrangentemente a Psicologia Analítica de Carl Gustav Jung, verificando padrões comportamentais e ideários com bases arcaicas e universais à psique (mente) humana, presentes nas cosmogonias dos povos, nos mitos, nas artes, na história e na experiência clínica, os quais nominou de arquétipos. Dentre eles, com destaque, o arquétipo materno.

Essas estruturas da psique humana repousam no inconsciente, influenciam e determinam, sobremaneira, a vida de todos.

Este artigo configura-se como uma aproximação entre o Direito Constitucional e a Psicologia Analítica, numa tentativa de evidenciar características inconscientes trintenárias da CRF/88 enquanto Constituição Arquetípica, transpassada pelo arquétipo materno, por isso, Constituição Mãe.

O método adotado é o indutivo ${ }^{2}$. No primeiro capítulo, faz-se uma justificativa interdisciplinar entre a Psicologia Analítica e o Direito Constitucional; no segundo capítulo, inicia-se o leitor à Psicologia de Carl Gustav Jung, explicando fundamentos de sua teoria; no terceiro capítulo, explica-se com mais vagar o arquétipo materno; no quarto capítulo, trata-se das impressões do constitucionalista José Joaquim Gomes Canotilho frente ao arquétipo materno; no quinto e último capítulo, exemplificam-se alguns traços maternais da $\mathrm{CRF} / 88$, traços estes, meramente sim-

$2 \mathrm{O}$ presente Artigo é composto conforme: PASOLD, Cesar Luiz. Metodologia da Pesquisa Jurídica: teoria e prática. 13ª ed. Florianópolis: Conceito Editorial, 2015. pp. 165-190. 
bólicos, que configurariam à Carta Magna caracteres de uma Grande Mãe (constituição arquetípica maternal) que vitima seus filhos (O Povo), quando mostra-se meramente uma constituição simbólica.

\section{JUSTIFICATIVA INTERDISCIPLINAR}

O Direito é multidimensional enquanto fato, valor e norma, REALE assim nos ensina ${ }^{3}$, e, enquanto fenômeno social complexo, (dimensões: histórica, social, filosófica, econômica, política), sua compreensão exige uma aproximação interdisciplinar que também dê conta dos seus conteúdos psíquicos, "la dimensión anímica", segundo $\mathrm{PUCCIO}^{4}$.

Natural é a tendência humana de interpretar separadamente o mundo interior do mundo exterior, dessa forma, a lei que é criada, pode apartar-se de seus pressupostos psíquicos que repousam na inconsciência, a interdisciplinaridade aqui proposta coloca-se como: “....aquella en la que el derecho es objeto de estúdio de otras disciplinas con la finalidad de aportar información y herramientas para compreenderlo en sus diversas dimensiones", nos dizeres de $\mathrm{PUCCIO}^{5}$.

$\mathrm{O}$ reconhecimento do inconsciente como substrato da psique $\mathrm{e}^{6}$ da razão como apenas uma entre as muitas funções da mente, pode assustar uma humanidade educada a desenvolver desde a infância a função mental racional.

3 REALE, Miguel. Fundamentos do direito. $3^{\text {a }}$ ed. São Paulo: Revista do Tribunais, 1988. 323 p. pp. $275-320$

4 PUCCIO, Fernando del Mastro. La dimensión anímica del derecho: una aproximación preliminar desde la psicología analítica. Derecho Pucp, n. 77, p.107-148, 2016. Sistema de Bibliotecas PUCP. http://dx.doi.org/10.18800/derechopucp.201602.006. p.144.

5 Idem, p. 108.

$6 \mathrm{Na}$ psicologia junguiana, a personalidade como um todo é denominada psique. Esta palavra latina significava originalmente "espírito" ou "alma", tendo porém passado, nos tempos modernos, a significar "mente", como em psicologia, a ciência da mente. A psique abrange todos os pensamentos, sentimentos e comportamento, tanto os conscientes como os inconscientes. Funciona como um guia que regula e adapta o indivíduo ao ambiente social e físico.

HALL, Calvin Springer; NORDBY, Vernon J. Introdução à psicologia junguiana. Tradução de Heloysa de Lima Dantas. 8ª ed. São Paulo: Cultrix, 2005. p. 25. 
Todavia, parece óbvio que se se faz ciência com a mente, se toda ciência é eminentemente racional, conhecer os mecanismos desta mente poderia poupar o cientista de enganos no estudo do objeto científico.

Isso não significa psicologizar o Direito ou qualquer ciência, mas, simplesmente tentar compreender o motor mental que transpassa todos os seres psíquicos que fazem ciência, para que não seja adornado de científicos, saberes oriundos da inconsciência e da irracionalidade.

Nesse sentido, a Psicologia Analítica de JUNG está alinhada à máxima grega atribuída a Pitágoras ${ }^{7}$ : $\gamma v \omega \theta$ r $\sigma \varepsilon \alpha v \tau o ́ v$ (Transliterado: gnothi sauton; "conheça a si mesmo"; em latim: nosce te ipsum).

Notório é que o homem não pode fugir ao filtro do psiquismo. Pode-se afirmar, sem titubear, que para o homem tudo é psíquico, só existe para o homem aquilo que encontra significação em seu psiquismo, é a partir dos conteúdos armazenados em sua mente que o indivíduo elabora uma realidade psíquica, afirmam FIORELLI e MANGINI ${ }^{8}$.

$\mathrm{O}$ desconhecimento do inconsciente carrega um grande problema: em sua faceta obscura, o homem torna-se vítima de si. Essa ignorância põe em curso "a mais fantástica de todas as leis da psicologia", conforme JUNG, a enantiodromia de Heráclito, ou função reguladora dos contrários, segundo a qual "um dia tudo reverte em seu contrário"9.

As descobertas e estudos desta parcela misteriosa da vida humana, o inconsciente, o "Mundo das Trevas", como afirma HILLMAN" ${ }^{10}$, foram e, paradoxalmente, continuam sendo altamente desconfortáveis para um mundo científico que prima pela razão e é advertido por FREUD de não sermos senhores em nossa própria casa. Neste aspecto, ROTH é esclarecedor ao afirmar que a rejeição ao reconhecimento da Psicanálise e do inconsciente, à época, "...significava um melindre coletivo em massa", justificando tais reações. ${ }^{11}$

\footnotetext{
${ }^{7}$ FRANZ, Marie-Louise von. Sonhos: um estudo dos sonhos de Jung, Descartes, Sócrates e outras figuras históricas. Tradução de Reinaldo Orth. Petrópolis: Vozes, 2011. p. 11.

${ }^{8}$ FIORELLI, José Osmir. MANGINI, Rosana Cathya Ragazzoni. Psicologia Jurídica. $7^{\text {a }}$ ed. São Paulo: Atlas, 2016. pp. 1 a 5.

9 JUNG, Carl Gustav. Psicologia do inconsciente. Tradução de Maria Luiza Appy. Petrópolis: Vozes, 1987. pp. 63-64.

${ }^{10}$ HILlMAN, James. O sonho e o mundo das trevas. Tradução de Gustavo Barcellos. Petrópolis: Vozes, 2013. pp. 78-88.

${ }^{11}$ ROTH, Wolfgang. Introdução à Psicologia de C. G. Jung. Tradução de Edgar Orth e Enio Paulo Giachini. Petrópolis: Vozes, 2011. p. 42.
} 
No que interessa a este artigo, a seara jurídica brasileira constitucional de 1988 e a análise dos aspectos inconscientes que influenciaram a feitura da CRF/88 parecem praticamente inexistentes. Nessa toada, de forma pretensamente analítica, se quer tocar as origens e estruturas inconscientes da Carta-Mor, com uma argumentação tendente para apontar as características maternais inconscientes da CRF/88.

Espera-se que esta singela leitura propicie ao leitor uma apreensão menos romântica e ingênua da $\mathrm{CRF} / 88$, que tenha ele um olhar consciente da LEX LEGUM, sem que isso resulte em pessimismo, ao contrário, é um olhar consciencioso que pode permitir a efetividade do texto constitucional.

É preciso enxergar, olhando para dentro, como diria $\mathrm{JUNG}^{12}$, e parar de fantasiar juridicamente, crendo num dicionário de utopias, como diria CAMPOS $^{13}$.

\section{INICIAÇÃO AO MUNDO DAS TREVAS}

"Falando mais diretamente: o mundo das trevas é a psique." James Hillman

O estudo do inconsciente foi iniciado na última década do Séc. XIX por FREUD ${ }^{14}$ e era bem conhecido de JUNG que, ainda em clínica universitária no ano de 1900, em Burghölzli, Zurique, Suíça, apresentou aos colegas a célebre obra Interpretação dos Sonhos, de FREUD, sem saber que aquele ano seria reconhecido mais tarde como o do nascimento da Psicanálise ${ }^{15}$.

JUNG criou a Psicologia Analítica e descobriu o inconsciente coletivo, após divergir do seu antigo mestre FREUD, entre outros moti-

\footnotetext{
${ }^{12}$ Frase célebre e proverbial de JUNG: Quem olha para fora sonha, quem olha para dentro enxerga.

${ }^{13}$ Ao tratar do anacronismo da CRF/88, Roberto Campos apontou: Costumo descrevê-la como um misto de regulamento trabalhista e dicionário de utopias. Foi em verdade o canto de cisne do nosso nacional-populismo.

CAMPOS, Roberto de Oliveira. A lanterna na popa: memórias. Vol. 2. $4^{\mathrm{a}}$ ed. rev., $1^{\mathrm{a}}$ reimpressão. Rio de Janeiro: Topbooks, 2004. p.1213.

${ }^{14}$ Sigmund Freud, 1856-1935, pai da Psicanálise.

${ }^{15}$ Idem, pp. 40 a 42.
} 
vos, por rejeitar ser o "príncipe herdeiro" da psicanálise, como queria o velho professor ${ }^{16}$. JUNG também não se conformou com a tese freudiana de relegar ao inconsciente apenas a função de local repositório de conteúdos reprimidos infantis, instintivos, sexuais, traumáticos e dolorosos, como será pormenorizado no item 2.1.1, do segundo capítulo deste artigo.

A ciência que trata do inconsciente é denominada de Psicologia Profunda ou das Profundezas, dividida basicamente em duas vertentes: Psicologia Psicanalítica ou Psicanálise, que segue a teoria de FREUD, e, Psicologia Analítica, de JUNG.

Segundo HILLMAN: "A psicologia profunda é onde hoje encontramos o mistério iniciatório, a longa jornada do aprendizado psíquico, a adoração dos ancestrais, o encontro com demônios e sombras, os sofrimentos do inferno". ${ }^{17} \mathrm{O}$ vaticínio de HILLMAN é compreensível ao estudioso da psicologia junguiana, acostumado à linguagem inatamente simbólica da psique.

Numa linguagem menos assustadora ao jurista e no contexto deste artigo, a psicologia profunda é aquela respaldada pela teoria de JUNG e que servirá para o princípio de uma conscientização das sutilezas inconscientes prescritas na $\mathrm{CRF} / 88$.

\subsection{ESTRUTURAS FUNDAMENTAIS: 0 INCONSCIENTE PESSOAL E O INCONSCIENTE COLETIVO ${ }^{18}$}

"O senhor cujo oráculo encontra-se em Delfos não fala nem esconde, mas dá um sinal". Heráclito

JUNG divide a psique ou mente humana em duas porções principais: inconsciente e consciente. Na consciência, encontra-se o Ego que dá unidade e continuidade à personalidade, seleciona os conteúdos que se tornarão conscientes, conforme combinações das funções dominantes da

\footnotetext{
16 JUNG, Carl Gustav. O eu e o inconsciente. Tradução de Dora Ferreira da Silva. 24 ed. Petrópolis: Vozes, 2012. pp. 15-16.

17 Idem. p. 106.

${ }^{18}$ Refoge ao propósito deste artigo esboçar toda a teoria analítica, tarefa impossível. Contudo, é indispensável transmitirmos sinteticamente os conceitos que nos levarão à compreensão do objetivo final delineado na introdução.
} 
mente (sensação, intuição, pensamento e sentimento) e atitudes predominantes da personalidade, extroversão ou introversão.

O inconsciente é dividido entre inconsciente pessoal, ou individual, e inconsciente coletivo.

Para tocar-se a CRF/88 com a Psicologia Analítica torna-se indispensável a compreensão das estruturas fundamentais da psique inconsciente nos moldes junguianos; é o que se faz a seguir.

\subsubsection{O INCONSCIENTE PESSOAL, OU INDIVIDUAL}

O inconsciente pessoal é tratado por JUNG como a psique subjetiva, pois pertence a cada individualidade humana de forma única, irrepetível, autêntica. Essa estrutura é formada e adquirida pela experiência pessoal, é o receptáculo de todo material psíquico que não passa pelo foco da consciência e suas aquisições retrocedem até a mais tenra infância.

Para JUNG, no inconsciente pessoal não estão apenas os conteúdos instintivos infantis reprimidos, de origem marcadamente sexual ou agressiva que encontram repulsa ou rejeição do Ego; este que, enquanto função consciente repressora das pulsões do $I d$, desarmônicas com a realidade externa, ocasiona recalques; tese de FREUD ${ }^{19}$; mas, também, verbis:

[...] lembranças perdidas, reprimidas (propositalmente esquecidas), evocações dolorosas, percepções que, por assim dizer, não ultrapassaram o limiar da consciência (subliminais), isto é, percepções dos sentidos que por falta de intensidade não atingiram a consciência e conteúdos que ainda não amadureceram para a consciência. $^{20}$

A multiplicidade e a quantidade imensurável de estímulos recebidos pelos sentidos torna impossível a conscientização de tudo, há limites para a psique consciente, o Ego age, então, como filtro da consciência, selecionando o volume de informações adequadas à existência da perso-

19 Id: parte primitiva e inconsciente da personalidade que busca continuamente prazer; Ego: responsável pelo contato do psiquismo com a realidade externa, medeia o Id e o Superego, contém elementos conscientes e inconscientes.

Idem, pp. 44-48.

${ }^{20}$ Idem. p. 58. 
nalidade de forma contínua e com identidade; função importante para HALL e NORDBY, pois: "caso contrário, ficaríamos assoberbados pela massa do material acumulado na consciência" ${ }^{21}$. Os demais conteúdos são depositados no inconsciente pessoal e podem dele ser evocados ou podem emergir nos sonhos como "restos do dia", resquícios subliminares dos eventos apresentados aos sentidos durante a vigília.

No inconsciente pessoal, as imagens acumuladas, de tom emocional comum, podem se agrupar formando núcleos dotados de energia própria, a isso se chama complexo, palavra corrente no vocabulário ocidental devido a JUNG. HALL afirma que: "Os complexos são o conteúdo básico do inconsciente pessoal" 22 .

Os complexos podem ser intensos a ponto de submeter a personalidade, por isso JUNG dizia que uma pessoa não tem um complexo, mas o complexo é que a tem.

HALL e NORDBY traduzem de forma simples e direta a assertiva em apreço:

Quando afirmamos que uma pessoa tem um complexo queremos dizer que vive tão intensamente preocupada com uma coisa que dificilmente consegue pensar noutra. No jargão atual, este indivíduo tem uma 'mania'. Um forte complexo é facilmente percebido por outras pessoas, embora quem o tem talvez não o perceba. ${ }^{23}$

O fato de ter sido JUNG um psicólogo empirista, não um filósofo ou teórico totalmente abstrato, fez com que ele não se satisfizesse com a teoria freudiana restritiva e redutora do inconsciente.

A necessidade do curador ferido de almas de compreender as doenças psíquicas e o ser humano, conjugada à volumosa prática clínica, especialmente no que diz respeito à análise dos sonhos de seus pacientes, inclinaram JUNG à descoberta e teorização do inconsciente coletivo.

Para FREUD, os sonhos são a via régia para o inconsciente; nos sonhos de pacientes e nos próprios sonhos, JUNG constatou a presen-

\footnotetext{
${ }^{21}$ Idem, p. 27.

${ }^{22}$ HALL, James A. Jung e a interpretação dos sonhos: manual de teoria e prática. Tradução de Álvaro Cabral. São Paulo: Cultrix, 2007. p. 14.

23 Ibidem, p. 29.
} 
ça de imagens comuns a culturas distantes e pessoas desconhecidas, que suplantavam a individualidade de cada paciente. Essas imagens também podiam e podem ser verificadas nos contos de fada, no folclore, na mitologia, nas religiões, nos esportes, nos frenesis mediúnicos, nas artes e até mesmo nos discos voadores, enquanto mito moderno visto no céu, tema que ocupou JUNG num livro ${ }^{24}$.

Essas imagens repousam no fundo da psique humana, num patamar abissal, no inconsciente coletivo, tratado adiante.

\subsubsection{O INCONSCIENTE COLETIVO}

“O inconsciente coletivo é a formidável herança espiritual do desenvolvimento da humanidade que nasce de novo na estrutura cerebral de todo ser humano." Carl Gustav Jung.

"Os conteúdos do inconsciente coletivo estimulam um padrão pré-formado de comportamento pessoal que o indivíduo seguirá desde o dia do nascimento". Calvin Hall e Vernon Nordby

$\mathrm{O}$ inconsciente coletivo é denominado por JUNG por psique objetiva, porque independe da subjetividade de qualquer um; para HALL, essa denominação "...quis enfatizar de modo especial que as profundezas da psique humana são objetivamente tão reais quanto o universo "real", exterior, da experiência consciente coletiva" 25 . Essa realidade objetiva psíquica é fácil de entender nos sonhos: quando se sonha, o sonho é a imediata realidade psíquica, para o homem a realidade só pode ser psíquica.

O inconsciente coletivo é uma parte da mente que independe da experiência pessoal prévia; não é uma aquisição pessoal, mas, sim, da espécie ${ }^{26}$.

Ao desconhecedor da teoria junguiana pode parecer, equivocadamente, que a expressão inconsciente coletivo remeta a uma inconsciên-

\footnotetext{
${ }^{24}$ Vide em: JUNG, Carl Gustav. Um mito moderno sobre coisas vistas no céu. Tradução de Eva Bornemann Abramowitz. 4a ed. Petrópolis: Vozes, 2011.

${ }^{25}$ Idem, p. 13.

${ }^{26}$ JUNG, Carl Gustav. Os arquétipos e o inconsciente coletivo. $8^{\mathrm{a}}$ ed. Tradução de Maria Luiza Appy e Mariana R. Ferreira da Silva. Petrópolis: Vozes, 2012. p. 51.
} 
cia geral e comum, como uma grande alma coletiva da humanidade, num sentido místico de que "todos somos um". Não é nada disso, apesar de que toda tradução é um pouco recriação; a expressão germânica original kollektive unbewusste não encontra paralelo com gemeinschaftlich unbewusste, ou seja: inconsciente comum, comunal ou comunitário ${ }^{27}$. Uma solução inicial para dissipar confusões semânticas é compreender o inconsciente coletivo como inconsciente inato, pois, trata-se de uma estrutura da psique (mente humana) pré-formada e adquirida pelo nascituro, dos seus ancestrais e de todos os ancestrais humanos e não humanos, conforme a teoria da evolução das espécies.

$\mathrm{O}$ inconsciente coletivo diz respeito às imagens primordiais universais herdadas dos antepassados da espécie humana, e, na linha evolutiva, das espécies das quais se originou o Homo sapiens; a essa universalidade remete o termo coletivo.

Sendo o cérebro o substrato da mente humana, as características fisiológicas constantes da evolução deste órgão determinam as elaborações da mente que sobre ele se erige, portanto, não só os fatores ambientais influenciam a psique, mas, intimamente, assim o fazem aqueles caracteres etiológicos e estruturais da fisiologia cerebral.

Se o inconsciente pessoal é a pátria dos complexos, o inconsciente coletivo é a nação dos arquétipos. Os arquétipos são as imagens primordiais, ancestrais, herdadas dos antepassados e que repousam no inconsciente coletivo, como potencialidades a serem preenchidas pelas experiências individuais de cada vivente. Estão presentes em toda a humanidade, independentemente de credos, raças, religiões e geografia.

Portanto, para JUNG, o homem não é uma tábula rasa, virtualmente o mundo já está pré-formado para aquele que nasce. No inconsciente coletivo, estão as tendências e até mesmo as determinações daquilo que se viverá. Nesse sentido, a psicologia junguiana demove o dogma religioso do livre arbítrio, um dos fundamentos das religiões monoteístas, segundo ONFRAY ${ }^{28}$ (os outros dois são a crença na imortalidade da alma e na existência de um Deus), e coloca em apuros a teoria do dolo, enquanto conduta consciente e livremente orientada à consecução criminal, para

\footnotetext{
27 WAHRIG-BURFEIND, Renate (Org.). Wahrig: Dicionário semibilíngue para brasileiros - Alemão. São Paulo: Martins Fontes, 2011. 1303 p. Tradução de Karina Jannini e Rita de Cássia Machado.

${ }^{28}$ ONFRAY, Michel. Tratado de Ateología: física de la metafísica. $3^{\mathrm{a}}$ ed. Buenos Aires: Ediciones de la Flor, 2006. p. 31.
} 
o enquadramento da culpabilidade no Direito Penal; visto que nem sempre (ou quase nunca!) se escolhe ao livre alvedrio o que se faz, perante as disposições arquetípicas do inconsciente.

$\mathrm{O}$ inconsciente coletivo ao remeter o homem para antes do seu nascimento não o leva a lembranças específicas dos seus antepassados, mas a uma configuração pré-disposta do desenvolvimento daquelas lembranças imemoriais arcaicas.

Exemplos: uma experiência arquetípica universal e inescapável é aquela que se dá no momento do luto. Por mais que se prepare alguém para o infortúnio previsível de algum ser querido, o momento da morte alheia fará com que surja em sua mente emoções que terão grande chance de fugir-lhe ao controle e fará com que tenha reações intimamente únicas, não iguais às de seus antepassados, mas tendentes a se repetirem em certa medida: o luto poderá trazer a depressão, o choro convulsivo, o silêncio, a dor permanente ou passageira, mas será sempre o luto, com seu caráter numinoso ${ }^{29}$, divino, aterrador, incompreensível, que explicita uma sensação de impotência sufocante, relembra a fragilidade da vida e sua brevidade - está o luto além das possibilidades humanas de dobrá-lo ao seu alvitre.

A expressão inglesa fall in love para o sentimento de estar apaixonado é outro arquétipo de clara compreensão, interessante é que fall enquanto tradução de queda remete à profundidade inconsciente do estado de paixão (quem está apaixonado cai no amor...) que submete o comportamento de todo apaixonado e possui características universais.

O estado patológico da depressão, tão comum e onipresente na civilização de hoje, também é arquetípico; remete-nos etimologicamente à submersão da alma humana na profundidade do inconsciente, quem está deprimido, ou seja, no fundo de si, perdeu as bases psíquicas de sustentação no inconsciente. HILLMAN aponta o quadro depressivo como oportunidade para reconexão, redescoberta do mundo das trevas, o inconscien$\mathrm{te}^{30}$.

Por fim, outro arquétipo comum de grande relevo e que interessa sumamente a este estudo é o arquétipo materno, visto a seguir.

\footnotetext{
29 Numinoso para a psicologia junguiana é aquilo que possui caráter divino, mágico, irresistível, além da potência humana, fortes afetos capazes de submeter o homem.

${ }^{30}$ Idem, p. 117.
} 


\section{O ARQUÉTIPO MATERNO}

"Cada criancinha, no mundo todo, herda um arquétipo materno". Calvin Hall e Vernon Nordby

"A primeira portadora da imagem da alma é sempre a mãe..." Carl Gustav Jung

O arquétipo materno é de fácil apreensão por parte de quem se defronta pela primeira vez com a psicologia das profundezas. Sendo indispensável, ainda ${ }^{31}$, nascer de uma mulher para ser humano, a imagem da mãe configura-se universalmente como estrutura psíquica de grande revelo para cada alma viva. Os inúmeros nascimentos, repetidos por milhões de anos, com a consequente relação mãe-filho, filho-mãe, sedimentaram no substrato psíquico universal a figura arquetípica da mãe.

O poder desse arquétipo é intenso, os arquétipos mais relevantes são os que dizem respeito à vida comum dos homens, não aos fatos fantásticos, como afirma JUNG: "Os fatos mais comuns da vida quotidiana, que se repetem eternamente, produzem os arquétipos mais poderosos, cuja atividade incessante é imediatamente reconhecível em toda parte, mesmo em nossa época racionalista" 32 .

Certo é que a figura da mãe pessoal (biológica, adotiva, avómãe, tia-mãe, etc) poderá parecer preponderar na imagem que cada um traz deste arquétipo; aqueles que desconhecem a própria mãe, ou não tiveram contanto algum com a mãe pessoal, também serão muito, ou até mais ${ }^{33}$, influenciados por este arquétipo, visto ser herdado, de importância psíquica estruturante e inescapável ao que nasce.

Todavia, essa influência da mãe pessoal é limitada, conforme $\mathrm{JUNG}^{34}$, sendo seu caráter mitológico oriundo, "muito mais", do arquétipo materno; somam-se a isso as características universais do arquétipo, que remetem a concepção materna individual para cima, para uma Grande Mãe, Magna mater, da humanidade toda, para um grande mito inato e todo poderoso. Em tempos de aquecimento global e de cons-

\footnotetext{
${ }^{31}$ Não se duvida que a evolução da medicina e da genética "logo" poderá permitir o nascimento autônomo, in vitro, numa máquina qualquer, do ser humano, sem que passe pelo ventre materno.

32 JUNG, Carl Gustav. A natureza da psique. Tradução de Mateus Ramalho Rocha. $8^{\mathrm{a}}$ ed. Petrópolis: Vozes, 2011. p. 101.

${ }^{33}$ Lembra-se da enantiodromia de Heráclito referida na introdução.

34 Idem, p. 89.
} 
cientização do homem a respeito de sua responsabilidade ecológica, essa Grande Mãe é a Terra viva, Mater natura, “... um gigantesco superorganismo, chamado Gaia, que se autorregula de tal forma que se torna apto para gerar permanente vida e se autorregenerar" $\left(!^{35}\right)$, nos dizeres de $\mathrm{BOFF}^{36}$.

Num crescendo, do mais íntimo ao mais universal, se isso for possível, os múltiplos aspectos ${ }^{37}$ maternais vão de Maria Madalena e das Pitonisas de Delfos à madrasta, sogra, tia, mãe, avó; à Via Láctea, Lua, Vênus, terra arada, árvore e árvore natalina, águas calmas do mar; indo além, à Igreja, Universidade, Cidade, Pátria, indo mais além, à Jerusalém Celeste, Iemanjá, Ishtar, Inana, Astaroth, até à Virgem (Deméter, Maria, Sofia), Isis, Nuit - numa espiral ascendente.

JUNG ensina que os traços característicos do arquétipo são "o maternal”, verbis:

[...] simplesmente a mágica autoridade do feminino; a sabedoria e a elevação espiritual além da razão; o bondoso, o que cuida, o que sustenta, o que proporciona as condições de crescimento, fertilidade e alimento; o lugar da transformação mágica, do renascimento; o instinto e o impulso favoráveis;... ${ }^{38}$.

Isso advém dos traços arquetípicos inerentes da Magna mater: a mãe é boa, nutritiva, terna, calorosa, dispensa cuidados, sua proteção é feroz. Dela todos se originam (útero sanguíneo) e a ela todos voltarão (cova, sepultura, tumba, como útero terrenal, mais quente que o ar e a água, onde ocorre a gestação da morte para a vida do além-túmulo).

Neste ponto, é preciso pausar para um giro de cento e oitenta graus, e, também, neste ponto, talvez o leitor tenha um insight ou maior compreensão do que seja o inconsciente: o arquétipo materno não pode embevecer ninguém, este é o segredo.

Parece haver uma tendência à totalidade em tudo o que é da natureza: noite e dia, luz e trevas, nascimento e morte, consciência e incons-

35 Percebe-se o arquétipo materno atuando na fala de Boff, nada mais natural, quem se preocupa com a sustentabilidade sonha com a proteção maternal!

36 BOFF, Leonardo. Sustentabilidade: o que é - o que não é. $2^{\mathrm{a}}$ ed. Petrópolis: Vozes, 2013. p. 115.

37 Passim, pp. 87 a 88.

38 Ibdem,. p. 88 
ciência, predador e presa, etc, há uma circularidade inerente à natureza. Se Heráclito nos disse que um dia tudo torna em seu contrário, e se JUNG coloca esse dizer como lei-mor psicológica, temos que começar a desconfiar do arquétipo materno para compreendermos o inconsciente coletivo.

Assim como falar, escrever, externar a outrem a respeito dos próprios defeitos é uma tarefa dificílima a qualquer humano, estando aí claramente um traço marcante do inconsciente pessoal ${ }^{39}$ - e inconsciente é justamente isso - o que nem mesmo se imagina: trazermos à tona o lado negativo do arquétipo materno não é tarefa fácil. Primeiro, por tender-se, erroneamente, a confrontar a imagem da mãe pessoal; segundo, por denegarem-se aspectos divinos, metafísicos, carregados de emoções, das deidades femininas de cada um.

Pois bem, à dificuldade; aplicando-se a enantiodromia para contradizer a citação retro transcrita de JUNG, poder-se-ia afirmar que o nãomaternal é:

simplesmente a crua submissão do feminino; a ignorância e a baixeza espiritual aquém da razão; o maldoso, o que descuida, o que deixa à mingua, o que não proporciona as condições de crescimento, é estéril e faminto; é o lugar da danação infernal, da morte; da frieza racional e do impulso desfavorável.

HOLLIS também é franco neste difícil ponto, verbis:

A mesma Grande Mãe que nos deu a vida nos transporta em direção à extinção, e tudo isso a serviço de um grande mistério que entontece a mente consciente, aterroriza o coração e agita a alma. Como o mais antigo dos ciclos míticos, o "ciclo do sacrifício", nós celebramos sua beneficência na mesa de jantar no mesmo momento em que somos comidos pela toupeira mordaz da mortalidade. Comam, aproveitem e sejam comidos. ${ }^{40}$

39 Note-se que nesta tarefa pode-se mesmo negar, com máxima sinceridade e franqueza, que se tenha qualquer defeito, ou seja, jazem os defeitos pessoais no fundo do inconsciente.

40 HOLLIS, James. Mitologemas: encarnações do mundo invisível. São Paulo: Paulus, 2005. Tradução de Gustavo Gerheim. p. 59. 
$\mathrm{O}$ culto à Deusa, oculta o lado sombrio da divindade. Este culto principia no útero, vai ao berço, à primeira namorada, à mulher, às entidades maternais (Igreja, Universidade, trabalho, associações de pais e mestres, academias, Estado, etc), ao Dia das Mães, à Virgem Maria... como dizer que esta mesma mãe, tão familiar, adorada e íntima é também danadora?

Toda a digressão até aqui feita nos encaminha para a conscientização do lado oculto da CRF/88 enquanto Carta Arquetípica Maternal, Magna mater lex legum, Grande Mãe Lei das Leis.

Esse enfrentamento é difícil, pois não se trata de mera repetição de ensinamentos constitucionais valiosos. Sem a acidez do gênio da literatura mundial, também bacharel jurídico, Franz Kafka, que ao criticar os ensinamentos obtidos na faculdade de Direito, dizia ter se alimentado de serragem já mastigada por milhares outros ${ }^{41}$, ousa-se fazer esse enfrentamento com a mãe, que se afasta de repetições.

O princípio desse embate foi feito por outro gênio, desta vez jurista, José Joaquim Gomes Canotilho, tratado a seguir.

\section{CANOTILHO FRENTE AO ARQUÉTIPO MATERNO}

Em sua célebre tese de doutorado intitulada: Constituição Dirigente e Vinculação do Legislador: Contributo para a compreensão das normas constitucionais programáticas ${ }^{42}$, que influenciou largamente os constitucionalistas brasileiros, bem como, a feitura da CRF/88, pois, a Constituição Federal Brasileira de 1988 possui marcadamente o traço de constituição dirigente, CANOTILHO teve um princípio de embate com o arquétipo materno.

A Constituição Dirigente é caracterizada por possuir um plano, presente em suas inúmeras normas programáticas que vinculam o legisla-

\footnotetext{
${ }^{41}$ A opinião de Kafka sobre os estudos do Direito era desiludida como sempre: "Intelectualmente, alimentei-me exclusivamente de serragem - serragem, aliás, que já havia sido mascada por milhares de maxilares antes de mim."

STRATHERN, Paul. Kafka em 90 minutos. Rio de Janeiro: Jorge Zahar, 2009. Tradução de Maria Luiza X. de A. Borges. p. 11.

${ }^{42}$ CANOTILHO, J. J. Gomes. Constituição Dirigente e Vinculação do Legislador. Contributo para a compreensão das normas constitucionais programáticas. $2^{\mathrm{a}}$ ed. Coimbra: Coimbra Editora, 2001. pp. 38-41.
} 
dor seguinte ao originário, de molde a que a legislação futura não destoe do plano constitucional inicial, nem se omita o legislador a criar leis conforme a vontade primeira do constituinte originário, sob pena de se configurar a inconstitucionalidade por omissão.

A rigor, esse repisado plano visaria uma evolução política, um ideal a ser alcançado adiante ${ }^{43}$, a Constituição Dirigente é notadamente defendida por juristas de formação marxista, o plano seria transformar o país em uma sociedade sem classes; este viés possuía a Constituição Portuguesa de 1976 , que, em seu art. $2^{\circ}$, previa a "transição para o socialismo", como nos alerta FERREIRA FILHO ${ }^{44}$.

Pois bem, é sintomático que ao tratar da Constituição enquanto arquétipo, o prolixo CANOTILHO, em apertadas quatro páginas, principie o tema com a seguinte advertência: "A análise da constituição dirigente move-se à 'superfície constitucional'. Não mergulhará, pois, na 'psicologia de profundidades', a fim de captar, no 'inconsciente coletivo', um "arquétipo constitucional", 45 .

Diz-se CANOTILHO ser sintomático ao iniciar seu texto, porque, ao mesmo tempo em que principia advertindo que sua tese foge à Psicologia das Profundezas, para elaboração da teoria da Constituição Dirigente, o arquétipo materno da Constituição, por ele tratado como "Grande Mãe" e "Gross-Mutter", em alemão, em tese, iluminaria:

...um aspecto obscuro da constituição dirigente: as constituições programáticas reconduzir-se-iam ao arquétipo da "Grande Mãe" (a mãe fala à criança, ao subdesenvolvido, ao carecido de protecção, ao que está em perigo, dando-lhe ajuda e espaço para o desenvolvimento e evolução);... ${ }^{46}$

Da leitura até aqui realizada a respeito do arquétipo materno, especialmente no capítulo terceiro, sem dúvida, as características programáticas da Constituição Dirigente, como constam do excerto supra, são notadamente pertencentes ao que JUNG denomina como o maternal.

\footnotetext{
43 FERREIRA FILHO, Manoel Gonçalves. Curso de direito constitucional. 26 ed. São Paulo: Saraiva. 1999. p. 19.

${ }^{44}$ FERREIRA FILHO. Manoel Gonçalves. Constituição e (in)governabilidade brasileira. São Paulo: Saraiva, 1995. p. 19.

${ }^{45}$ Idem, p. 38.

46 Ibidem, p. 39.
} 
Todavia, CANOTILHO refoge à possibilidade arquetípica constitucional e à interdisciplinaridade com a Psicologia, pois:

Mesmo que se aceite a posição de MARTI, segundo a qual constitui meia verdade dizer-se que a ordem jurídica é uma "criação puramente racional", a psicologização da teoria da constituição conduz a resultados dificilmente aceitáveis ${ }^{47}$.

Posição diametralmente oposta à deste $\operatorname{artigo~}^{48}$, pois, não se trata de psicologizar o Direito, mas de entender a psicologia do jurista que faz o Direito, para que aspectos do seu inconsciente não tolham sua produção científica.

Finalizando o tópico, CANOTILHO nos diz: "Deixando a constituição dirigente no 'regaço' da 'Grande-Mãe' ..., enfrente-se agora a exigência da racionalidade" 49 .

Nesta finalização, percebe-se que o texto de CANOTILHO denota certo desconforto, pois, foge ao embate com a teoria do inconsciente; esse desconforto pode ser presumido, hipoteticamente, como um aspecto inconsciente de sua psique, é sintoma de afeto, por isso, afirmou-se desde o início ser sintomático, em termos psicológicos.

Com todas as vênias e colocando-se o autor deste artigo no devido lugar, bastante humilde, perante um gigante jurista como CANOTILHO, não é possível aceitar, conscienciosa e facilmente, que uma aproximação do Direito Constitucional com a Psicologia do Inconsciente "conduza a resultados dificilmente aceitáveis", sem maiores justificativas.

No mesmo sentido, o da dificílima aceitação, superar esse embate teórico interdisciplinar com um aliviado: “...enfrente-se agora a exigência da racionalidade", denota, ao menos, desinteresse relativamente ao tema, não ousa-se jamais supor desconhecimento do célebre jurista a respeito da Psicologia Profunda. Também, infere-se, da frase desfecho de CANOTILHO, que a racionalidade da psicologia não interessa ao Direito, seria uma psicologização, pois, obviamente, o jurista de Coimbra não seria deselegante a ponto de tratar a Psicologia Profunda como irracional.

\footnotetext{
${ }^{47}$ Ibidem, p. 39.

${ }^{48}$ Vide Capítulo 1, que trata da justificativa interdisciplinar. 49 Ibidem, p. 41.
} 
Justamente, a "exigência da racionalidade" é que conduz à interdisciplinaridade apta à compreensão de uma ciência multidimensional e oriunda de fenômenos sociais complexos, como é o Direito.

Os traços do arquétipo materno que configuram a CRF/88 como Grande Mãe parecem ser marcantes, frente aos conhecimentos da Psicologia Profunda até aqui expostos, ainda que em apertadíssima síntese, e serão exemplificados no próximo e final capítulo, em conjunto ao simbolismo do texto constitucional.

\section{A CRF/88 COMO GRANDE MÃE (CONSTITUIÇÃO ARQUETÍPICA MATERNAL) QUE VITIMA SEUS FILHOS (O POVO) QUANDO MOSTRA-SE MERAMENTE COMO CONSTITUIÇÃO SIMBÓLICA (FALACIOSA)}

Marcelo Neves, em sua clássica obra apresentada para obtenção do cargo de Professor titular da UFPE: A constitucionalização simbóli$c a^{50}$, ensina que muitas disposições constitucionais são aprovadas, por grupos antagônicos, justamente pela "perspectiva da ineficácia" da norma aprovada consensualmente; transfere-se o conflito para o futuro, amainando "um conflito político interno" "51; este seria um dos efeitos da legislação simbólica, a rigor, uma falácia.

Como afirmado desde o início deste artigo, JUNG apoia-se na enantiodromia de Heráclito para estabelecer uma lei fundamental da Psicologia, que sustenta a relação dialética entre o consciente e o inconsciente: um dia tudo torna em seu contrário.

A CRF/88 enquanto "constituição simbólica", tendo como característica a presença de normas em seu texto, cuja efetividade não tem perspectiva de realização, e que serve apenas para apaziguar grupos politicamente antagônicos, jogando soluções hipotéticas para o futuro, como justificativa ao eleitorado, como leciona NEVES, revela a enantiodromia arquetípica em operação na Carta Magna, bem como, comprova a tese da confecção de tais normas falaciosas sob a égide do inconsciente coletivo: conscientemente se quer que a Constituição realize suas promessas ma- 
ternais, insconscientemente, se é órfão. Vejam-se alguns exemplos a seguir ${ }^{52}$.

\subsection{EDUCAÇÃO COMO DIREITO DE TODOS E DEVER DO ESTADO (ART. 205)}

É notório que a baixa qualidade do ensino fundamental e médio obriga as famílias que têm condições financeiras a matricularem seus filhos em escolas particulares; paradoxalmente, um fenômeno antigo, faz com que as faculdades e universidades públicas, apesar das cotas raciais e sociais, sejam frequentadas majoritariamente por alunos oriundos de famílias com posses. Enquanto o rico estuda na Federal, o pobre estuda nas faculdades particulares, à noite e com professores de menor qualificação. A ordem se inverte: se nos estágios do ensino fundamental e médio os melhores professores são das escolas particulares, no ensino universitário a qualificação dos professores das faculdades e universidades públicas são, em regra, superiores.

\subsection{ERRADICAÇÃO DA POBREZA (ART. 3ㅇ, III)}

Erradicar a pobreza é fundamento da República Federativa do Brasil, contudo, o constituinte originário esqueceu-se: primeiro, de que há muitos que optam pela pobreza, talvez com a esperança de entrar nos Céus ${ }^{53}$, não têm vontade de sair desse estado; segundo, a imensa maioria de muitos cidadãos pertencentes a parcelas historicamente estigmatizadas nunca terão condições sociais de sair da pobreza (negros, pobres, prostitutas, homossexuais, deficientes físicos, favelados, ex-presidiários, exdrogaditos, minorias afins). RIBEIRO ${ }^{54}$ há muito tempo, esclareceu que

52 BRASIL. PRESIDÊNCIA DA REPÚBLICA. Constituição da República Federativa do Brasil de 1998. Brasília, DF. Disponível em: http:// http://www.planalto.gov.br/ccivil_03/constituicao/constituicaocompilado.htm . Acessado em 20/08/2017

${ }^{53}$ Bíblia Sagrada, Mateus Cap. 19, versículo 24: É mais fácil o camelo entrar pelo buraco da agulha do que o rico entrar no Reino de Deus.

${ }^{54}$ RIBEIRO, Darcy. O povo brasileiro: a formação e o sentido do Brasil. $3^{\text {a }}$ ed. São Paulo: Global, 2015. pp. 157-171. 
neste aspecto está arraigado na cultura nacional um espírito de "feitoria", não o de um Estado que dá condições de promoção social aos desprovidos ou estigmatizados; terceiro, conquistas sociais não se fazem com passes de mágica em forma de artigos legislativos. Neste aspecto, temos que concordar com o incompreendido e criticado CAMPOS:

Conquistas sociais não se alcançam por simples inserção no texto constitucional. Dependem da produtividade da sociedade, das prioridades orçamentárias, da criatividade dos indivíduos, da conjuntura das empresas. Se a pobreza fosse extinguível por decreto, seria crueldade não editar anualmente uma Constituição incorporando novos avanços progressistas. ${ }^{55}$

Apesar de reconhecer-se que o Direito possui em suas origens influências religiosas e mágicas que até hoje perduram ${ }^{56}$, segundo CAR$\mathrm{NEIRO}^{57}$, já passou da hora de, em pleno Século XXI, deixar de lado a crença na magia das palavras.

\subsection{ASSISTÊNCIA SOCIAL SEM CONTRAPARTIDA FINANCEIRA (ART. 203)}

Ignorando as projeções de crescimento populacional, a carga tributária, as perspectivas fiscais, criou-se a assistência social sem contrapartida financeira aos idosos e incapazes de ofício laboral; todavia, no mesmo patamar do salário mínimo, de tal forma que muitos cidadãos optam por não contribuir para a aposentadoria, tendo em vista que, esperando mais um pouco, obtêm a mesma renda com o alcance da idade necessária.

\footnotetext{
55 MERCADANTE, Paulo (Org). [et al]. Constituição de 1988: o avanço do retrocesso. Rio de Janeiro: Rio Fundo Editora, 1990. p. 138.

56 Veja-se o dito popular e foral segundo o qual os juízes pensam serem deuses e os desembargadores terem absoluta certeza disso.

57 CARNEIRO, Rafael Prince. A César o que é de Deus: magia, mito e sacralidade do direito. 2008. 44 p. Dissertação (Bacharelado em Direito) - Faculdade de Direito da Universidade de São Paulo - USP, São Paulo.
} 
Este dispositivo constitucional parece seguir uma lógica meramente contábil (tirar-se-ia de quem tem mais para dar a quem tem menos), ao invés de seguir-se a lógica econômica (a riqueza se produz, a produtividade e a poupança geram riqueza), sem sentido por desobedecer a primários cálculos atuariais, ou seja, garante-se um direito sem dizer quem paga a conta e sem prever se haverá caixa para pagamento.

Estes exemplos são singelos e poderiam ser multiplicados em profusão ante a prolixidade constitucional benigna da CRF/88, emendada por 96 (noventa e seis) vezes, até a data da finalização deste artigo.

\section{CONSIDERAÇÕES FINAIS}

"Apesar de aparecermos como pequenas ondas, o mar inteiro está em nossas costas e somos um com ele. Nenhuma onda pode existir por si mesma".Swami Vivekananda

Tomada a consciência da Grande Mãe Constitucional Arquetípica de 1988, a CRF/88, ou ao menos abertas as portas para uma melhor compreensão de seus aspectos ocultos no inconsciente coletivo, com o surgimento do interesse para futuras, melhores e aprofundadas pesquisas, por mentes superiores a do autor deste artigo, cumpriu-se a meta, enfrentou-se a imago inconsciente da "mãe" e um novo patamar amplificado de consciência surge e permite uma visão mais abrangente da realidade constitucional pátria.

A justificativa interdisciplinar proposta entre a Psicologia Analítica e o Direito Constitucional espera-se ter sido frutífera e que abranja outras áreas do Direito; foram demonstrados fundamentos da Psicologia Analítica que poderão ser úteis a prospecções futuras; o arquétipo materno deixa de ser um desconhecido perigoso para ser, quem sabe, uma fonte de criatividade jurídica; reconhecendo a grande importância do constitucionalista José Joaquim Gomes Canotilho, ousou-se discordar pontualmente de trecho de sua tese de doutoramento, no sentido de dar relevo à Psicologia Profunda como aliada do Direito Constitucional; por fim, conjuntamente à clássica obra de Marcelo Neves, exemplificou-se alguns traços maternais da CRF/88, traços estes meramente simbólicos, que configurariam à Carta Magna caracteres de Grande Mãe (constituição arquetípica maternal) que vitima seus filhos (O Povo) quando mostra-se meramente uma constituição simbólica. 
Com a licença do paciente leitor, ante todas as ideias até aqui esmiuçadas e a proximidade do aniversário de trinta anos da Constituição Cidadã, como dizia Ulysses Guimarães, opina-se que, dentre outros exemplos: erradicar a pobreza, educar a todos de forma gratuita e assistir a idosos e inválidos com um dinheiro mágico, vindo sabe-se lá de onde, são promessas maternais calorosas, ternas e nutritivas de uma Grande Mãe, inexistente na dura realidade social e que, vivendo no imaginário nacional, traveste-se em pérfida mãe que oculta em seu inato simbolismo suas inverdades, com promessas áureas sempre jogadas adiante, num país tido sempre e incansavelmente como o país do futuro.

O futuro chegou, é hora de enxergarmos olhando para dentro deste país, cujas entranhas estão dispostas num texto que deve ser levado muito a sério: a Constituição da República Federativa do Brasil de 1988, que entrará na maturidade em 2018.

\section{REFERÊNCIAS BIBLIOGRÁFICAS}

BOFF, Leonardo. Sustentabilidade: o que é - o que não é. $2^{\mathrm{a}}$ ed. Petrópolis: Vozes, 2013.

BRASIL. PRESIDÊNCIA DA REPÚBLICA. Constituição da República Federativa do Brasil de 1998. Brasília, DF. Disponível em: http:// http://www.planalto.gov.br/ccivil_03/constituicao/constituicaocompilado.ht m . Acessado em 20/08/2017.

CAMPOS, Roberto de Oliveira. A lanterna na popa: memórias. Vol. 2. $4^{\mathrm{a}}$ ed. rev., $1^{a}$ reimpressão. Rio de Janeiro: Topbooks, 2004.

CANOTILHO, J. J. Gomes. Constituição Dirigente e Vinculação do Legislador. Contributo para a compreensão das normas constitucionais programáticas. $2^{\mathrm{a}}$ ed. Coimbra: Coimbra Editora, 2001.

CARNEIRO, Rafael Prince. A César o que é de Deus: magia, mito e sacralidade do direito. 2008. 44 p. Dissertação (Bacharelado em Direito) - Faculdade de Direito da Universidade de São Paulo - USP, São Paulo.

FERREIRA FILHO. Manoel Gonçalves. Constituição e (in)governabilidade brasileira. São Paulo: Saraiva, 1995.

São Paulo: Saraiva. 1999.

. Curso de direito constitucional. $26^{\mathrm{a}}$ ed.

FRANZ, Marie-Louise von. Sonhos: um estudo dos sonhos de Jung, Descartes, Sócrates e outras figuras históricas. Tradução de Reinaldo Orth. Petrópolis: Vozes, 2011.

FIORELLI, José Osmir. MANGINI, Rosana Cathya Ragazzoni. Psicologia Jurídica. $7^{\text {a }}$ ed. São Paulo: Atlas, 2016. 
HALL, Calvin Springer; NORDBY, Vernon J. Introdução à psicologia junguiana. Tradução de Heloysa de Lima Dantas. $8^{\mathrm{a}}$ ed. São Paulo: Cultrix, 2005.

HALL, James A. Jung e a interpretação dos sonhos: manual de teoria e prática. Tradução de Álvaro Cabral. São Paulo: Cultrix, 2007.

HILLMAN, James. O sonho e o mundo das trevas. Tradução de Gustavo Barcellos. Petrópolis: Vozes, 2013.

HOLLIS, James. Mitologemas: encarnações do mundo invisível. Tradução de Gustavo Gerheim. São Paulo: Paulus, 2005.

JUNG, Carl Gustav. A natureza da psique. Tradução de Mateus Ramalho Rocha. 8. ed. Petrópolis: Vozes, 2011.

O eu e o inconsciente. Tradução de Dora Ferreira da Silva. $24^{\mathrm{a}}$ ed. Petrópolis: Vozes, 2012.

. Os arquétipos e o inconsciente coletivo. $8^{\mathrm{a}}$ ed. Tradução de Maria Luiza Appy e Mariana R. Ferreira da Silva. Petrópolis: Vozes, 2012. . Psicologia do inconsciente. Tradução de Maria Luiza Appy. Petrópolis: Vozes, 1987. . Um mito moderno sobre coisas vistas no céu. Tradução de Eva Bornemann Abramowitz. 4a ed. Petrópolis: Vozes, 2011.

MERCADANTE, Paulo (Org). [et al]. Constituição de 1988: o avanço do retrocesso. Rio de Janeiro: Rio Fundo Editora, 1990.

NEVES, Marcelo. A constitucionalização simbólica. São Paulo: Martins Fontes, 2007.

ONFRAY, Michel. Tratado de Ateología: física de la metafísica. $3^{\mathrm{a}}$ ed. Buenos Aires: Ediciones de la Flor, 2006.

PASOLD, Cesar Luiz. Metodologia da Pesquisa Jurídica: Teoria e prática. 13 ed. - Florianópolis: Conceito Editorial, 2015.

PUCCIO, Fernando del Mastro. La dimensión anímica del derecho: una aproximación preliminar desde la psicología analítica. Derecho Pucp, n. 77, p.107148, 2016. Sistema de Bibliotecas PUCP. http://dx.doi.org/10.18800/derechopucp.201602.006.

REALE, Miguel. Fundamentos do direito. $3^{\mathrm{a}}$ ed. São Paulo: Revista do Tribunais, 1988.

RIBEIRO, Darcy. O povo brasileiro: a formação e o sentido do Brasil. $3^{\text {a }}$ ed. São Paulo: Global, 2015.

ROTH, Wolfgang. Introdução à Psicologia de C. G. Jung. Tradução de Edgar Orth e Enio Paulo Giachini. Petrópolis: Vozes, 2011.

STRATHERN, Paul. Kafka em 90 minutos. Tradução de Maria Luiza X. de A. Borges. Rio de Janeiro: Jorge Zahar, 2009.

WAHRIG-BURFEIND, Renate (Org.). Wahrig: Dicionário semibilíngue para brasileiros - Alemão. Tradução de Karina Jannini e Rita de Cássia Machado. São Paulo: Martins Fontes, 2011. 